\title{
Genome-wide association analysis of total cholesterol and high-density lipoprotein cholesterol levels using the Framingham Heart Study data
}

\author{
Li Ma', Jing Yang ${ }^{1}$, H Birali Runesha², Toshiko Tanaka3,4, Luigi Ferrucci ${ }^{4}$ Stefania Bandinelli5 and Yang Da*1
}

\begin{abstract}
Background: Cholesterol concentrations in blood are related to cardiovascular diseases. Recent genome-wide association studies (GWAS) of cholesterol levels identified a number of single-locus effects on total cholesterol (TC) and high-density lipoprotein cholesterol (HDL-C) levels. Here, we report single-locus and epistasis SNP effects on TC and HDL-C using the Framingham Heart Study (FHS) data.

Results: Single-locus effects and pairwise epistasis effects of 432,096 SNP markers were tested for their significance on log-transformed TC and HDL-C levels. Twenty nine additive SNP effects reached single-locus genome-wide significance $\left(p<7.2 \times 10^{-8}\right)$ and no dominance effect reached genome-wide significance. Two new gene regions were detected, the RAB3GAP1-R3HDM1-LCT-MCM6 region of chr02 for TC identified by six new SNPs, and the OSBPL8-

ZDHHC17 region (chr12) for HDL-C identified by one new SNP. The remaining 22 single-locus SNP effects confirmed previously reported genes or gene regions. For TC, three SNPs identified two gene regions that were tightly linked with previously reported genes associated with TC, including rs599839 that was 10 bases downstream PSRC1 and $3.498 \mathrm{~kb}$ downstream CELSR2, rs4970834 in CELSR2, and rs4245791 in ABCG8 that slightly overlapped with ABCG5. For HDL-C, LPL was confirmed by 12 SNPs 8-45 kb downstream, CETP by two SNPs 0.5-11 kb upstream, and the LIPG-ACAA2 region by five SNPs inside this region. Two epistasis effects on TC and thirteen epistasis effects on HDL-C reached the significance of "suggestive linkage". The most significant epistasis effect $\left(p=5.72 \times 10^{-13}\right)$ was close to reaching "significant linkage" and was a dominance $\times$ dominance effect of HDL-C between LMBRD1 (chr06) and the LRIG3 region (chr12), and this pair of gene regions had six other $D \times D$ effects with "suggestive linkage".

Conclusions: Genome-wide association analysis of the FHS data detected two new gene regions with genome-wide significance, detected epistatic SNP effects on TC and HDL-C with the significance of suggestive linkage in seven pairs of gene regions, and confirmed some previously reported gene regions associated with TC and HDL-C.
\end{abstract}

\section{Background}

Total cholesterol (TC) is related to coronary diseases and high-density lipoprotein (HDL-C) cholesterol is antiatherogenic. Genome-wide association studies (GWAS) and human genetic studies have identified a number of genes and gene regions affecting cholesterol phenotypes including TC and HDL-C [1-11]. A meta-analysis of HDL-C levels that include the FHS data has previously

\footnotetext{
* Correspondence: yda@umn.edu

1 Department of Animal Science, University of Minnesota, USA Full list of author information is available at the end of the article
}

been published [2]. An early report on FHS [12] analyzed TC and HDL-C but used $100 \mathrm{k}$ SNPs and a sample size that was much smaller than the current FHS sample size. Epistasis analysis of TC and HDL-C was unavailable. Here, we apply a quantitative genetics approach to detect additive or dominance single-locus effects and epistasis effects on log-transformed TC and HDL-C using 432,096 SNP markers and over 6000 individuals in FHS. The epistasis effects we tested included additive $x$ additive (A $\times \mathrm{A})$, additive $\times$ dominance $(\mathrm{A} \times \mathrm{D})$ or dominance $\times$ additive $(D \times A)$, and dominance $\times$ dominance $(D \times D)$ effects, 
with genetic interpretations of allele $x$ allele, allele $\times$ genotype or genotype $\times$ allele, and genotype $\times$ genotype interactions. The single-locus analysis was intended to detect new targets or confirm existing targets using a method of analysis different from those used in previous reports based on an extended Kempthorne model that allows Hardy-Weinberger disequilibrium and linkage disequilibrium [13] for GWAS analysis of the FHS data while the epistasis analysis of TC and HDL-C was the first such attempt using the FHS data and the $500 \mathrm{k}$ SNP panel.

\section{Results}

The single-locus tests detected nine SNPs with additive (or allelic) effects on TC and twenty SNPs with additive effects on HDL-C that reached genome-wide significance (Tables 1-2). No dominance effect reached genome-wide significance. Among the twenty nine SNP effects, twenty were new effects that were not reported in previous studies and nine were previously reported to be associated with various cholesterol phenotypes [1-12]. Seven SNPs identified two new gene regions while the remaining twenty two SNPs confirmed previously reported gene regions. Two epistasis effects on TC and thirteen epistasis effects on HDL-C representing seven pairs of gene regions reached the significance of "suggestive linkage".

\section{Single-locus effects}

For TC, nine SNPs with additive (or allelic) effects reached genome-wide significance with $\mathrm{p}<7.2 \times 10^{-8}$ (Table 1). Six SNPs inside or near four genes identified a new chr02 region containing RAB3GAP1, R3HDM1, LCT and MCM6 to be associated with TC (Figure 1A). Of the six SNPs in the RAB3GAP1-R3HDM1-LCT-MCM6 region, five SNPs were inside genes and one SNP was 4.2 kb upstream MCM6. The most significant SNP in this region was rs2322660 in intron 12 of $L C T$ (Table 1). The RAB3GAP1-R3HDM1-LCT-MCM6 region contained two other genes $(Z R A N B 3$ and $U B X D 2)$ that did not have significant SNPs. Eleven other SNPs spanning a $1.23 \mathrm{Mb}$ region (Figure 1A) that includes $R A B 3 G A P 1-R 3 H D M 1-$ $L C T-M C M 6$ had $\mathrm{p}$-values between $1.27 \times 10^{-5}$ and $7.13 \times$ $10^{-7}$, including one SNP upstream $A C M S D$, one SNP in $A C M S D$, two SNPs in YSK4, one SNP in R3HDM1, one SNP in $U B X D 2$ (also named $U B X N 4$ according to NCBI

Table 1: Single-locus SNP effects for TC with genome control (GC) adjusted $P<7.2 \times 10^{-8}$.

\begin{tabular}{|c|c|c|c|c|c|c|c|c|}
\hline \multirow[b]{2}{*}{ SNP } & \multirow[b]{2}{*}{ Chr } & \multirow[b]{2}{*}{ Position } & \multirow[b]{2}{*}{ Gene Region } & \multirow[b]{2}{*}{ Reported SNP effect } & \multirow[b]{2}{*}{ MAF } & \multicolumn{2}{|c|}{ Effect Type \& P value } & \multirow[b]{2}{*}{ Effect Size } \\
\hline & & & & & & Genotype & Additive & \\
\hline \multirow[t]{2}{*}{ rs4970834 } & 1 & 109814880 & $\begin{array}{c}\text { CELSR2a } \\
\text { (intron 28) }\end{array}$ & Non-HDL-C [5-7] & 0.18 & $1.10 \mathrm{E}-08$ & $1.75 \mathrm{E}-09$ & $0.146 \pm 0.023$ \\
\hline & & & & $\mathrm{TC}[8]$ & & & & \\
\hline \multirow[t]{2}{*}{ rs599839 } & 1 & 109822166 & $\begin{array}{c}10 \text { bases } \\
\text { downstream }\end{array}$ & LDL-C $[6,7,9,10]$ & 0.22 & $8.72 \mathrm{E}-14$ & $2.46 \mathrm{E}-14$ & $0.174 \pm 0.021$ \\
\hline & & & $P S R C 1^{a}$ & Non-HDL-C [5] & & & & \\
\hline rs4245791 & 2 & 44074431 & $A B C G 8$ (intron 3) & & 0.32 & $1.82 \mathrm{E}-07$ & 3.33E-08 & $\begin{array}{c}-0.127 \pm \\
0.021\end{array}$ \\
\hline rs6730157 & 2 & 135907088 & $\begin{array}{l}\text { RAB3GAP1 } \\
\text { (intron 17) }\end{array}$ & LDL-C: $P=0.018[2]^{b}$ & 0.45 & $8.51 \mathrm{E}-08$ & $2.16 \mathrm{E}-08$ & $0.113 \pm 0.019$ \\
\hline rs12465802 & 2 & 136381348 & $\begin{array}{l}\text { R3HDM1 } \\
\text { (intron 7) }\end{array}$ & LDL-C: $P=0.022[2]^{b}$ & 0.44 & 2.63E-08 & 7.98E-09 & $0.117 \pm 0.019$ \\
\hline rs4954280 & 2 & 136420690 & $\begin{array}{c}\text { R3HDM1 } \\
\text { (intron18) }\end{array}$ & LDL-C: $P=0.007[2]^{b}$ & 0.33 & $1.49 \mathrm{E}-07$ & 5.87E-08 & $0.114 \pm 0.02$ \\
\hline \multirow[t]{3}{*}{ rs2322660 } & 2 & 136557319 & $L C T$ (intron 12) & LDL-C: $P=0.055[2]^{b}$ & 0.35 & $2.42 \mathrm{E}-08$ & 7.08E-09 & $\begin{array}{c}-0.120 \pm \\
0.019\end{array}$ \\
\hline & & & & $\mathrm{TC}: \mathrm{P}=0.003-0.005[17]$ & & & & \\
\hline & & & & LDL-C: $P=0.002-0.0005$ [17] & & & & \\
\hline rs309180 & 2 & 136614255 & MCM6 (intron 11) & LDL-C: $P=0.057[2]^{b}$ & 0.36 & $2.43 \mathrm{E}-08$ & 8.39E-09 & $\begin{array}{c}-0.119 \pm \\
0.019\end{array}$ \\
\hline rs632632 & 2 & 136638216 & $\begin{array}{c}4.2 \mathrm{~kb} \text { upstream } \\
\text { MCM6 }\end{array}$ & LDL-C: $P=0.216[2]^{b}$ & 0.36 & $2.50 \mathrm{E}-08$ & $1.03 \mathrm{E}-08$ & $\begin{array}{c}-0.118 \pm \\
0.019\end{array}$ \\
\hline
\end{tabular}

a This gene was reported to be associated with TC [1].

b Available at http://www.sph.umich.edu/csg/abecasis/public/lipids2008/ 
Table 2: Single-locus SNP effects for HDL-C with genome control (GC) adjusted $P<7.2 \times 10^{-8}$.

\begin{tabular}{|c|c|c|c|c|c|c|c|c|}
\hline \multirow[b]{2}{*}{ SNP } & \multirow[b]{2}{*}{ Chr } & \multirow[b]{2}{*}{ Position } & \multirow[b]{2}{*}{ Gene Region } & \multirow[b]{2}{*}{$\begin{array}{l}\text { Reported SNP } \\
\text { effect }\end{array}$} & \multirow[b]{2}{*}{ MAF } & \multicolumn{2}{|c|}{ Effect Type \& P value } & \multirow[b]{2}{*}{ Effect Size } \\
\hline & & & & & & Genotype & Additive & \\
\hline rs17482753 & 8 & 19832646 & $8 \mathrm{~kb}$ downstream $L P L^{\mathrm{a}}$ & Triglyceride [7] & 0.10 & $1.27 \mathrm{E}-08$ & $3.50 \mathrm{E}-09$ & $\begin{array}{c}-0.191 \pm \\
0.031\end{array}$ \\
\hline rs10503669 & 8 & 19847690 & $23 \mathrm{~kb}$ downstream $L P L^{\mathrm{a}}$ & HDL-C $[4,11]$ & 0.09 & $3.75 \mathrm{E}-08$ & $1.14 \mathrm{E}-08$ & $\begin{array}{c}-0.189 \pm \\
0.031\end{array}$ \\
\hline rs17410962 & 8 & 19848080 & $23 \mathrm{~kb}$ downstream $L P L^{\mathrm{a}}$ & & 0.12 & $2.75 \mathrm{E}-08$ & 4.27E-09 & $0.173 \pm 0.028$ \\
\hline rs17489268 & 8 & 19852045 & $27 \mathrm{~kb}$ downstream $L P L^{\mathrm{a}}$ & & 0.27 & $2.28 \mathrm{E}-10$ & 5.97E-11 & $0.141 \pm 0.02$ \\
\hline rs17411031 & 8 & 19852310 & $28 \mathrm{~kb}$ downstream $L P L^{\mathrm{a}}$ & HDL-C [7] & 0.27 & $3.06 \mathrm{E}-10$ & $7.21 \mathrm{E}-11$ & $-0.14 \pm 0.02$ \\
\hline rs17489282 & 8 & 19852518 & $28 \mathrm{~kb}$ downstream $L P L^{\mathrm{a}}$ & & 0.25 & $2.33 \mathrm{E}-09$ & $6.54 \mathrm{E}-10$ & $0.14 \pm 0.021$ \\
\hline rs4922117 & 8 & 19852586 & $28 \mathrm{~kb}$ downstream $L P L^{\mathrm{a}}$ & & 0.25 & $2.28 \mathrm{E}-09$ & 7.73E-10 & $\begin{array}{c}-0.124 \pm \\
0.019\end{array}$ \\
\hline rs17411126 & 8 & 19855272 & $31 \mathrm{~kb}$ downstream $L P L^{\mathrm{a}}$ & & 0.27 & $6.14 \mathrm{E}-10$ & $1.23 \mathrm{E}-10$ & $0.138 \pm 0.02$ \\
\hline rs765547 & 8 & 19866274 & $42 \mathrm{~kb}$ downstream $L P L^{\mathrm{a}}$ & & 0.27 & $1.60 \mathrm{E}-10$ & 3.07E-11 & $-0.142 \pm 0.02$ \\
\hline rs11986942 & 8 & 19867445 & $43 \mathrm{~kb}$ downstream $L P L^{\mathrm{a}}$ & & 0.33 & $2.22 \mathrm{E}-07$ & $5.53 \mathrm{E}-08$ & $0.112 \pm 0.02$ \\
\hline rs1837842 & 8 & 19868290 & $44 \mathrm{~kb}$ downstream $L P L^{\mathrm{a}}$ & & 0.27 & $2.14 \mathrm{E}-10$ & 4.09E-11 & $0.142 \pm 0.02$ \\
\hline rs1919484 & 8 & 19869676 & $45 \mathrm{~kb}$ downstream $L P L^{\mathrm{a}}$ & & 0.27 & $4.12 \mathrm{E}-10$ & $7.21 \mathrm{E}-11$ & $\begin{array}{c}-0.143 \pm \\
0.021\end{array}$ \\
\hline rs17259942 & 12 & 77072077 & OSBPL8-ZDHHC17 & & 0.12 & 8.61E-08 & $1.81 \mathrm{E}-08$ & $0.168 \pm 0.028$ \\
\hline rs9989419 & 16 & 56985139 & HERPUD 1-CETPa & HDL-C $[4,7]$ & 0.40 & 4.57E-13 & $5.96 \mathrm{E}-14$ & $\begin{array}{c}-0.147 \pm \\
0.019\end{array}$ \\
\hline rs1800775 & 16 & 56995236 & $0.5 \mathrm{~kb}$ upstream CETPa & $\mathrm{HDL}-\mathrm{C}[3,12]$ & 0.45 & $1.54 \mathrm{E}-29$ & $1.64 \mathrm{E}-30$ & $0.242 \pm 0.02$ \\
\hline rs7240405 & 18 & 47159090 & $L I P G^{a}-A C A A 2^{b}$ & & 0.16 & 8.01E-08 & $1.58 \mathrm{E}-08$ & $\begin{array}{c}-0.145 \pm \\
0.024\end{array}$ \\
\hline rs4939883 & 18 & 47167214 & LIPG $\mathrm{a}_{-} A C A A 2^{\mathrm{b}}$ & $\mathrm{HDL}-\mathrm{C}[1,2]$ & 0.17 & $1.07 \mathrm{E}-07$ & $1.85 \mathrm{E}-08$ & $0.142 \pm 0.024$ \\
\hline rs1943981 & 18 & 47169815 & $L I P G \mathrm{a}-A C A A 2^{\mathrm{b}}$ & & 0.17 & $1.49 \mathrm{E}-07$ & $2.50 \mathrm{E}-08$ & $0.142 \pm 0.024$ \\
\hline rs2156552 & 18 & 47181668 & $\angle I P G^{a}-A C A A 2^{b}$ & HDL-C $[3,4]$ & 0.16 & 5.87E-08 & $1.14 \mathrm{E}-08$ & $\begin{array}{c}-0.146 \pm \\
0.024\end{array}$ \\
\hline rs6507945 & 18 & 47243912 & LIPG $\mathrm{a}_{-} A C A A 2^{\mathrm{b}}$ & & 0.43 & $4.34 \mathrm{E}-08$ & $6.91 \mathrm{E}-09$ & $0.113 \pm 0.018$ \\
\hline
\end{tabular}

a This gene was reported in [1-4].

b This gene was reported in [3].

[14]), two SNPs in $L C T$, and three SNPs downstream DARS (data not shown). These less significant results in the same neighborhood should add to the significance of the RAB3GAP1-R3HDM1-LCT-MCM6 region to TC. Three SNPs identified two genes that were tightly linked with previously reported genes associated with TC [1]. These three SNPs were rs599839 that was 10 bases downstream PSRC1 (chr01) and $3.498 \mathrm{~kb}$ downstream CELSR2, rs4970834 in intron 28 of CELSR2, and rs4245791 in intron 3 of $A B C G 8$ (chr02) that slightly overlapped with $A B C G 5$, where CELSR2 and ABCG5 regions were reported to be associated with TC in a recent GWAS report [1]. PSRC1 and ABCG8 also were reported to affect low-density lipoprotein cholesterol (LDL-C) [2-
$4,6,7,9,10]$. The SNP (rs599839) that was 10 bases downstream PSRC1 had the most significant single-locus effect on TC ( $\left.\mathrm{p}=3.7 \times 10^{-16}\right)$, while the SNP inside CELSR2 (rs4970834) had the second most significant single-locus effect on TC $\left(\mathrm{p}=1.29 \times 10^{-10}\right)$.

For HDL-C, twenty SNPs with additive effects reached genome-wide significance (Table 2). SNP rs17259942 identified a new gene region associated with HDL-C, the OSBPL8-ZDHHC17 region (q21.2, Figure 1B), with rs17259942 being $117 \mathrm{~kb}$ downstream OSBPL 8 and $85 \mathrm{~kb}$ upstream $Z D H H C 17$ [15]. According to NCBI [14], the OSBPL8-ZDHHC17 region contained three pseudogenes (RPL7AP59, RPL21P98 and RPL7P43) and rs17259942 was $18 \mathrm{~kb}$ downstream RPL21P98 and $43 \mathrm{~kb}$ 


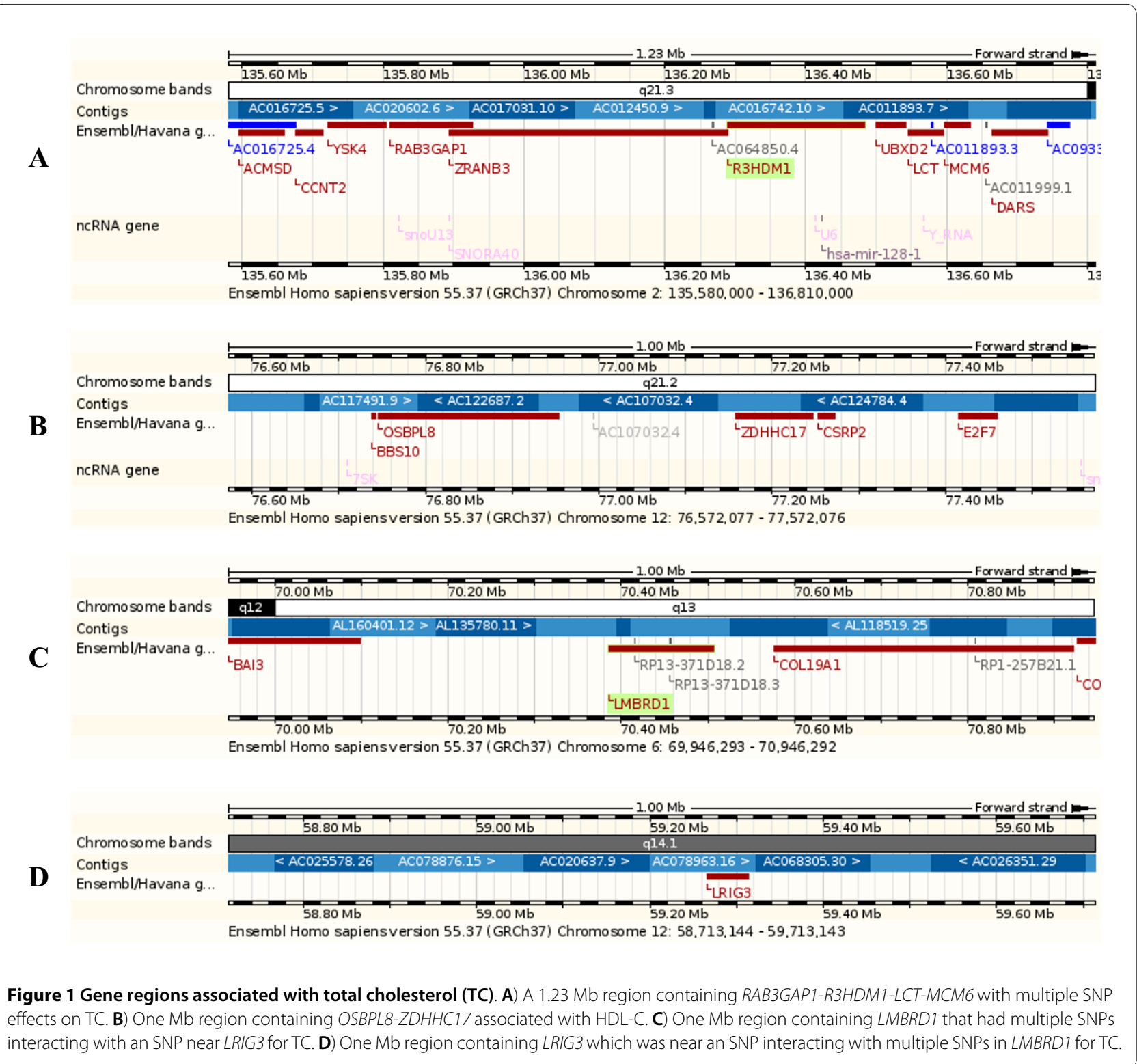

upstream RPL7P43. The other nineteen SNPs confirmed previously reported gene regions, including twelve SNPs 8-45 kb downstream $L P L$, two SNPs 0.5-11 kb upstream CETP, and five SNPs in the LIPG-ACAA2 region (39.812 $\mathrm{kb}$ downstream $L I G$ and $65.963 \mathrm{~kb}$ upstream $A C A A 2$ ) [1$4,7,11,12]$. LPL, CETP and LIPG were reported to be associated with HDL-C in four recent GWAS reports [14] while $A C A A 2$ was reported in [3]. The SNP nearest to CETP (rs1800775) was the most significant effect $(\mathrm{p}=$ $\left.8.61 \times 10^{-34}\right)$ in this study.

QQ plot for single SNP tests on TC and HDL-C showed that $\mathrm{p}$-values of significant results all deviated from the expected p-values under the null hypothesis (Figure 2).

\section{Epistasis effects}

Two epistasis effects on TC and thirteen epistasis effects on HDL-C reached the significance of suggestive linkage defined in [16] (Table 3). The two epistasis effects on TC involved two different pairs of gene regions while the thirteen epistasis effects on HDL-C involved five different pairs of gene regions, so that the fifteen epistasis effects identified seven pairs of gene regions. Eight SNPs in introns 1, 5, 7, 9, and 14 of $L M B R D 1$ (chr06) (Figure 1C) interacted with a chr12 SNP about $53 \mathrm{~kb}$ from LRIG3 (q14.1, Figure 1D) and all these eight pairs had D $\times \mathrm{D}$ effects on HDL-C. One of the eight epistasis effects involving intron 14 of $L M B R D 1$ was the most significant epistasis effect that was close to reaching "significant 

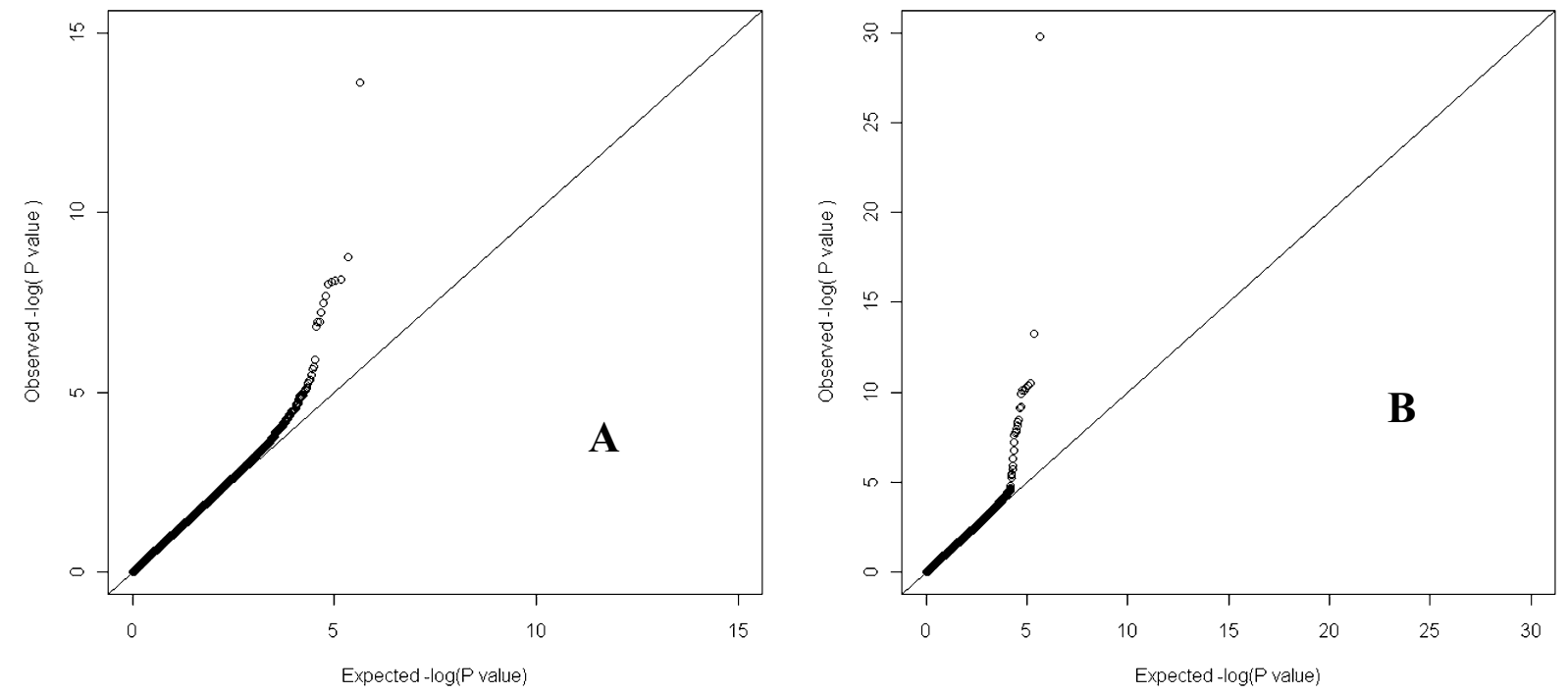

Figure 2 QQ plots for single-SNP whole genome association tests of total cholesterol (TC) and high-density lipoprotein cholesterol (HDLC). A) TC. B) HDL-C.

linkage" defined in [16] or genome-wide significance with $5 \%$ Bonferroni corrected type-I error.

Among the seven different pairs of gene regions with epistasis effects, four pairs had $\mathrm{A} \times \mathrm{A}$ effects, one pair had $\mathrm{A} \times \mathrm{D}$ effect, and two pairs had $\mathrm{D} \times \mathrm{D}$ effects (Table 3 ). For the A $\times$ A effect on TC involving chr04 and chr10, the A-T gamete had the highest TC value while the A-G gamete had the lowest TC value (Table 4). This showed that the $\mathrm{G}$ and $\mathrm{T}$ alleles of rs705169 on chr10 had significantly different effects when combined with the A allele of rs4437278 on chr04, noting that rs705169 did not have significant single-locus effect. The same phenomenon was also observed for the other three $\mathrm{A} \times \mathrm{A}$ effects in Table 4. For the $\mathrm{A} \times \mathrm{D}$ effect, the A-GG allele-genotype combination had the highest TC value while the G-GG allele-genotype combination had the lowest $\mathrm{TC}$ value. The two $\mathrm{D} \times \mathrm{D}$ effects were on HDL-C. For the $\mathrm{D} \times \mathrm{D}$ effect of rs4706271 $\times$ rs6581219 representing the eight pairs of $\mathrm{D} \times \mathrm{D}$ effects involving the same gene regions, GT-GG had the highest HDL-C value while GG-GG had the lowest HDL-C value. For the remaining $\mathrm{D} \times \mathrm{D}$ effect of rs12596869 $\times$ rs6506699 representing the two $\mathrm{D} \times \mathrm{D}$ effects of the same gene regions, CC-AG had the highest HDL-C value while CC-AA had the lowest HDL-C value (Table 4).

\section{Discussion}

The single-locus results in this study had strong confirmations with existing studies. For TC, we confirmed CELSR 2 and ABCG5 reported in $[1,8]$. These confirmed TC results should be considered as strong confirmation because our study had no overlapping samples with studies of $[1,8]$. We detected seven effects on TC in the RAB3GAP1-R3HDM1-LCT-MCM6 region with the SNP in $L C T$ being the most significant. Six of these seven effects had p-values for LDL-C in the range of 0.0070.056 from a meta-analysis ([2], Table 1$)$. This could be an indication about the significance on TC from a metaanalysis because LDL-C is calculated from TC [17]. A study in FINRISK cohorts with 14,140 individuals reported that $L C T$ was associated with both TC and LDL$C$ with p-values in the range of 0.0005-0.005 [18]. In Silico replication using 1231 Italian subjects from the InCHIANTI cohort [19] generally lacked confirmation for the $\mathrm{TC}$ results in Table 1. The first three markers had p-values in the range of 0.005-0.07 while the other effects had p-values greater than 0.14 from the InCHIANTI cohort. The biological function of $L C T$ for digesting lactose could be a reason for agreements and disagreements in replicating $L C T$ effects on cholesterol. $L C T$ affects lactose digestion and long-term consumption of lactose in rats was found to affect aortic cholesterol levels [20]. Therefore, dietary lactose levels that have not been considered by human GWAS could have affected the $L C T$ results of different studies. MCM6 contains two of the regulatory regions for $L C T$ [21] so that the significant effects in or near MCM6 (Table 1) could be due to MCM6's regulatory role to $L C T$. HDL-C had twenty significant SNP effects, but only one SNP identified a new gene region (OSBPL8$Z D H H C 17)$ while all the other SNPs confirmed previously reported gene regions, although only seven of the twenty significant SNPs for HDL-C were reported previ- 
Table 3: Epistasis effects for TC and HDL-C with the significance of suggestive linkage.

\begin{tabular}{|c|c|c|c|c|c|c|c|c|c|c|c|c|c|}
\hline \multirow[b]{2}{*}{ SNP1 } & \multirow[b]{2}{*}{ Chr1 } & \multirow[b]{2}{*}{ Pos1 } & \multirow[b]{2}{*}{ Gene1 } & \multirow[b]{2}{*}{ MAF1 } & \multirow[b]{2}{*}{ SNP2 } & \multirow[b]{2}{*}{ Chr2 } & \multirow[b]{2}{*}{ Pos2 } & \multirow[b]{2}{*}{ Gene2 } & \multirow[b]{2}{*}{ MAF2 } & \multicolumn{2}{|c|}{ P value } & & \multirow[b]{2}{*}{ Effect } \\
\hline & & & & & & & & & & Genotype & & stasis & \\
\hline \multicolumn{14}{|c|}{ TC } \\
\hline rs4437278 & 4 & 12488199 & U6a (174 kb) & 0.15 & rs705169 & 10 & 125285443 & GRP26(140 kb) & 0.49 & $4.49 \mathrm{E}-10$ & AA & $5.93 \mathrm{E}-12$ & $0.249 \pm 0.036$ \\
\hline rs4738150 & 8 & 72607907 & U8 (120 kb) & 0.40 & rs16918936 & 9 & 33009027 & APTX, LOC646808 & 0.04 & $4.68 \mathrm{E}-13$ & $A D$ & $1.29 \mathrm{E}-12$ & $-1.348 \pm 0.188$ \\
\hline \multicolumn{14}{|c|}{ HDL-C } \\
\hline rs10476539 & 5 & 91991628 & $A C 026781.5^{\mathrm{a}}(62 \mathrm{~kb})$ & 0.18 & rs2392885 & 8 & 129003117 & $P V T 1^{\mathrm{a}}$ & 0.28 & $2.63 \mathrm{E}-10$ & $A A$ & $2.99 \mathrm{E}-12$ & $-0.269 \pm 0.037$ \\
\hline rs4706271 & 6 & 70390132 & $L M B R D 1$ (intron 14) & 0.41 & rs6581219 & 12 & 59213144 & LRIG3(53 kb) & 0.42 & 7.67E-11 & $\mathrm{DD}$ & $5.72 \mathrm{E}-13$ & $-0.412 \pm 0.056$ \\
\hline rs7741758 & 6 & 70412380 & LMBRD1(intron9) & 0.41 & rs6581219 & 12 & 59213144 & LRIG3(53 kb) & 0.42 & $5.73 \mathrm{E}-10$ & $\mathrm{DD}$ & 4.60E-12 & $-0.388 \pm 0.054$ \\
\hline rs9346333 & 6 & 70426479 & LMBRD 1(intron8) & 0.41 & rs6581219 & 12 & 59213144 & LRIG3(53 kb) & 0.42 & $1.39 \mathrm{E}-10$ & $\mathrm{DD}$ & $1.16 \mathrm{E}-12$ & $-0.398 \pm 0.054$ \\
\hline rs9351772 & 6 & 70428200 & LMBRD1(intron8) & 0.41 & rs6581219 & 12 & 59213144 & LRIG3(53 kb) & 0.42 & $5.38 \mathrm{E}-10$ & $\mathrm{DD}$ & $4.25 \mathrm{E}-12$ & $-0.390 \pm 0.055$ \\
\hline rs7762400 & 6 & 70445634 & LMBRD1(intron7) & 0.41 & rs6581219 & 12 & 59213144 & $L R I G 3(53 \mathrm{~kb})$ & 0.42 & $4.41 \mathrm{E}-10$ & DD & $3.52 \mathrm{E}-12$ & $-0.388 \pm 0.054$ \\
\hline rs9294851 & 6 & 70457629 & LMBRD1(intron5) & 0.41 & rs6581219 & 12 & 59213144 & LRIG3(53 kb) & 0.42 & $2.83 \mathrm{E}-10$ & DD & $2.22 \mathrm{E}-12$ & $-0.392 \pm 0.054$ \\
\hline rs9354890 & 6 & 70504296 & LMBRD1(intron 1) & 0.41 & rs6581219 & 12 & 59213144 & LRIG3(53 kb) & 0.42 & $5.54 \mathrm{E}-10$ & $\mathrm{DD}$ & $4.18 \mathrm{E}-12$ & $-0.388 \pm 0.054$ \\
\hline rs9364063 & 6 & 70514750 & $\angle M B R D 1(8 \mathrm{~kb})$ & 0.41 & rs6581219 & 12 & 59213144 & $L R I G 3(53 \mathrm{~kb})$ & 0.42 & 4.65E-10 & $\mathrm{DD}$ & 4.46E-12 & $-0.386 \pm 0.054$ \\
\hline rs2787520 & 6 & 106821428 & ATG5(48 kb) & 0.35 & rs7236739 & 18 & 20800715 & CABLES1(intron4) & 0.31 & $2.98 \mathrm{E}-10$ & $A A$ & $2.48 \mathrm{E}-12$ & $-0.211 \pm 0.029$ \\
\hline rs2842169 & 10 & 128330713 & AL583860.7a (85 kb) & 0.10 & rs4756344 & 11 & 36765284 & C11orf74(84 kb) & 0.26 & $3.56 \mathrm{E}-10$ & AA & $3.73 \mathrm{E}-12$ & $0.348 \pm 0.049$ \\
\hline rs17623128 & 16 & 77630108 & $A C 092724.2^{\mathrm{a}}(114 \mathrm{~kb})$ & 0.33 & rs6506699 & 18 & 9775566 & RAB31 & 0.49 & $4.65 \mathrm{E}-10$ & DD & $2.78 \mathrm{E}-12$ & $-0.449 \pm 0.062$ \\
\hline rs12596869 & 16 & 77630380 & $A C 092724.2^{\mathrm{a}}(114 \mathrm{~kb})$ & 0.33 & rs6506699 & 18 & 9775566 & $R A B 31$ & 0.49 & $3.81 \mathrm{E}-10$ & DD & $2.30 \mathrm{E}-12$ & $-0.451 \pm 0.062$ \\
\hline
\end{tabular}

a This was an RNA gene. 
Table 4: Frequency and effect of gamete, allele-genotype or genotype-genotype combination in each epistasis effect with statistical significance of suggestive linkage.

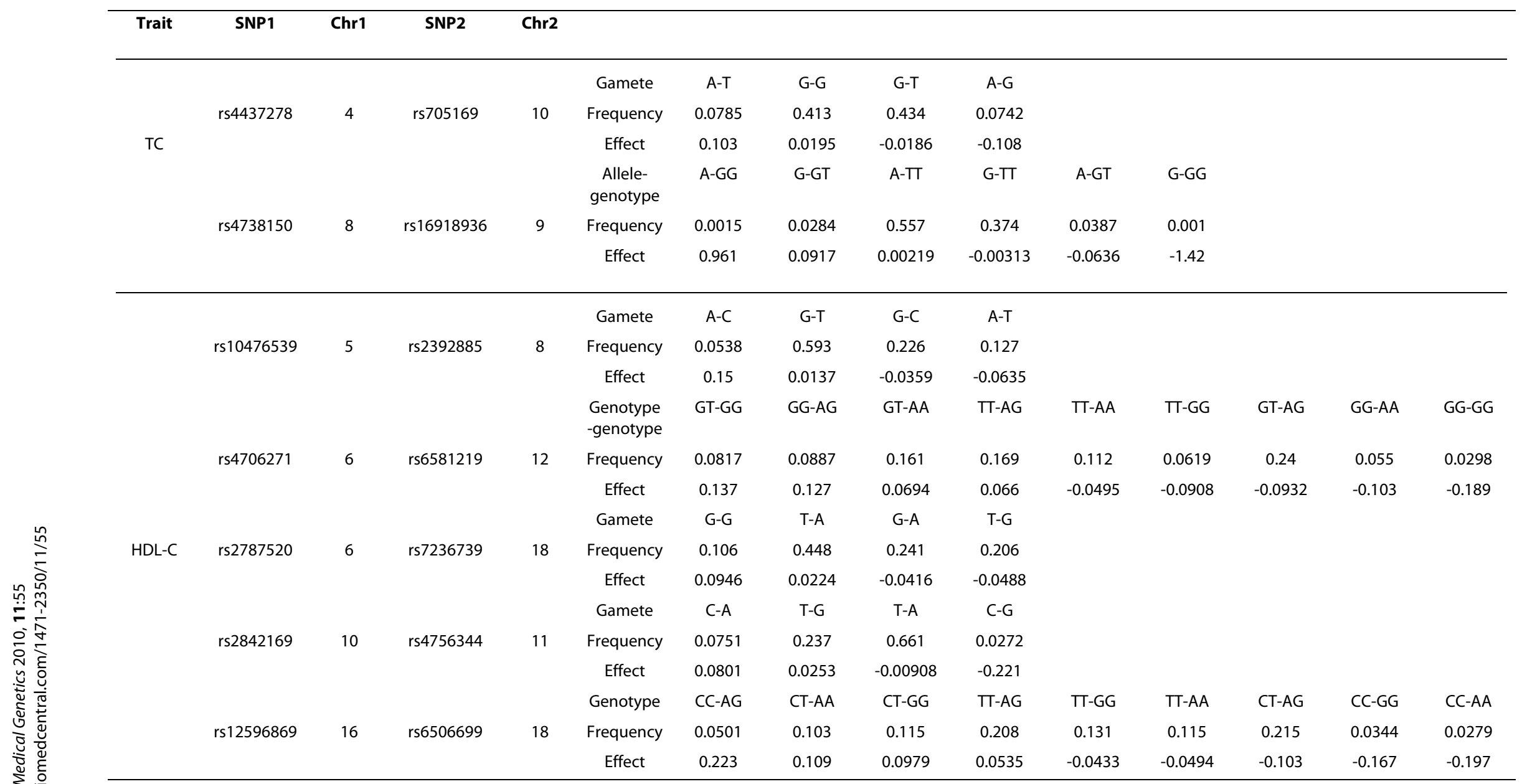


ously (Table 2). OSBPL8 encodes a group of intracellular lipid receptors and suppresses $A B C A 1$ [22], and $A B C A 1$ was found to affect HDL-C level [23,24]. For HDL-C, the InCHIANTI cohort did not confirm the effects in the $L I P G-A C A A$ region $(\mathrm{p}>0.55$ ) but confirmed the other effects. In light of different samples and different methods of data analysis between our study and those in previous reports, the confirmations of gene results we observed for TC and HDL-C should be considered strong confirmations. This study used log-transformed TC and HDL-C values while recent GWAS on TC [1] and HDL-C [1-4] used the original observations of TC and HDL-C that deviated from normal distribution. However, singlelocus effects from our study and previous studies [1-4] had remarkable mutual confirmation, indicating that single-locus analysis was somewhat robust to data distribution and possibly to methods of analysis.

Epistasis effects on TC and HDL-C were not reported in other GWAS so that a comparison between our epistasis results and those from others was unavailable. We detected eight SNP pairs indicating the interaction between gene $L M B R D 1$ and gene LRIG3 with the significance of suggestive linkage. Both $L M B R D 1$ and LRIG3 encode membrane proteins. $L M B R D 1$ gene is involved in the transportation and metabolism of vitamin B12 which is important for metabolism of branched chain amino acids and odd chain fatty acids [25]. Replication using the InCHIANTI cohort did not confirm the epistasis results $(\mathrm{p}>0.15)$.

The statistical power of epistasis testing is less than that for testing a single-locus effect, particularly for epistasis effects involving dominance such as $\mathrm{A} \times \mathrm{D}$ and $\mathrm{D} \times \mathrm{D}$ effects, with $\mathrm{D} \times \mathrm{D}$ effect being the most difficult to detect. The reason for this difficulty was due to the fact that higher-order effects explain less phenotypic variation even if the effect sizes were the same as lower-order effects [13]. The reduced power for epistasis testing could have contributed to the fact that the epistasis effects we detected only reached 'suggestive linkage' although the sample size was over 6000 . The data analysis of this study showed that pairwise analysis was sensitive to outliers. This was due to the fact that artificially significant epistasis effects could occur when rare combinations of loci had extreme genotypic values by chance. This may happen when outliers exist due to the large number of pairwise effects arising from the large number of pairwise combinations. For example, over 466 billion pairwise effects $(93,353,260,560$ pairs $\times 5$ effects per pair $=$ $466,766,302,800$ pairwise effects) were tested per trait in this study. A small fraction of random association between rare frequencies and outliers in opposite directions among a large number of pairs could yield a long list of artificially significant epistasis results. Therefore, dealing with outliers such as removing outliers and using data transformation is important in pairwise analysis. Pairwise analysis is computationally intensive but timely analysis is possible using parallel computing. Using 784 processor cores on the SGI Altix XE 1300 Linux cluster system with $2.66 \mathrm{GHz}$ Intel Clovertown processor at the Minnesota Supercomputer Institute, the completion of pairwise epistasis analysis required about 15 hours per trait.

\section{Conclusions}

Genome-wide association analysis of the FHS data detected new single-locus and epistasis effects on TC and HDL-C and confirmed some previously reported effects. Additive effects were the primary single-locus effects of TC and HDL-C while epistasis effects involved allele $x$ allele, allele $\times$ genotype (or genotype $\times$ allele), and genotype $\times$ genotype interactions.

\section{Methods}

\section{Phenotype and SNP data}

The FHS GWAS data (version 2) had 6575 individuals with SNP genotypes of the $500 \mathrm{k}$ SNP panel from dbGAP. Of the 6575 individuals, 6431 had observations on TC and 6078 individuals had observations on HDL-C. A total of 496,858 SNP markers had known chromosome locations and 432,096 of these SNP markers with minor allele frequencies greater than or equal to 0.01 were analyzed.

\section{Statistical Analysis}

Original TC and HDL-C observations deviated from normality and had outliers (Figure 3A, D). The Box-Cox transformation analysis [26] implemented by the R statistical package [27] showed that the log-transformation was approximately the best transformation to achieve normality for those two traits (Figure 3B-C, E-F). One TC outlier, the highest $\mathrm{TC}$ value, was removed from the data analysis while no HDL-C outlier was removed. Log-transformed TC values were adjusted for blood sugar, body mass index, smoking status, and sex that had significant effects on $\log (\mathrm{TC})$. Age, age-squared, cholesterol treatment, and alcohol consumption were also tested for significant effects on $\log (\mathrm{TC})$ but were not included in the phenotypic model because they were insignificant. Log(HDL-C) was adjusted for age, age-squared, cholesterol treatment, blood sugar, body mass index, smoking status, number of cigars smoked, alcohol consumption and sex. Age was insignificant for HDL-C but was included because age-squared was nearly significant ( $\mathrm{p}<$ 0.0543). Single-locus and epistasis effects for both traits were tested using the extended Kempthorne model that allows Hardy-Weinberg disequilibrium and linkage disequilibrium [13]. For each SNP, three effects were tested, genotypic, additive (A) and dominance (D) effects. For each SNP pair, five effects were tested, two-locus genotypic effect, $\mathrm{A} \times \mathrm{A}, \mathrm{A} \times \mathrm{D}, \mathrm{D} \times \mathrm{A}$, and $\mathrm{D} \times \mathrm{D}$ epistasis 

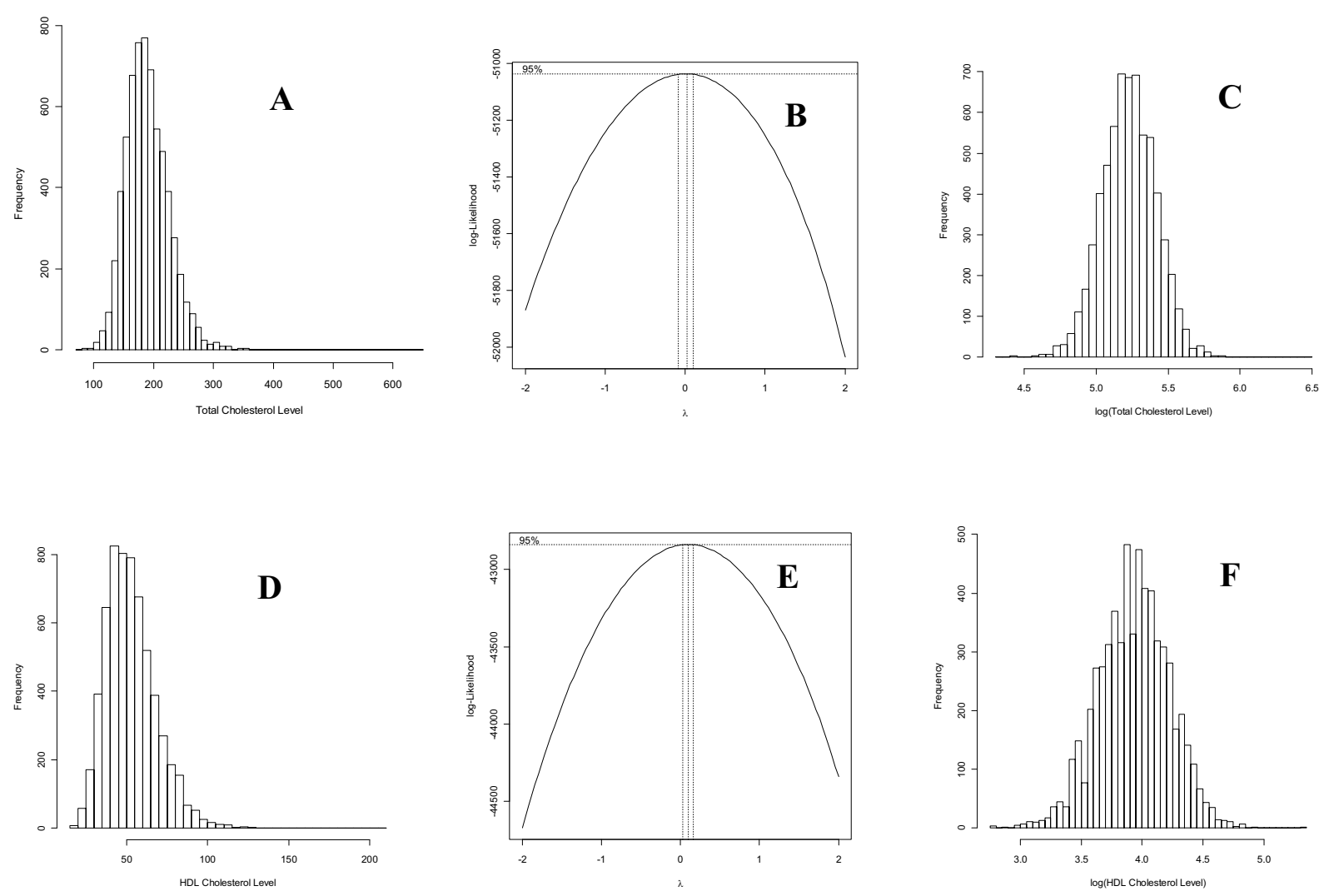

Figure 3 Distributions of total cholesterol (TC) and high-density lipoprotein cholesterol (HDL-C) in original scales and in log-transformed scales. A) Distribution of TC in original scale deviated from normality and had an outlier to the far right. B) The Box-Cox maximum likelihood analysis showed that log-transformation $(\lambda \approx 0)$ was the best transformation to achieve normality for TC. C) Log-transformed TC values achieved normality. One outlier to the far right was removed from the data analysis. D) Distribution of HDL-C in original scale deviated from normality and had some outliers to the right. E) The Box-Cox maximum likelihood analysis showed that log-transformation $(\lambda \approx 0)$ was the best transformation to achieve normality for HDL-C. F) Log-transformed HDL-C values achieved normality without serious outliers.

effects. The EPISNPmpi parallel computing program [28] with a modification to implement a generalized least squares (GLS) analysis to account for sib correlations [29] was used to implement the statistical tests of single-locus and pairwise epistasis effects. For single-locus tests, $\mathrm{p}=$ $7.2 \times 10^{-8}$ was used as the threshold p-value to declare genome-wide significance [30]. To assess genome-wide significance of pairwise epistasis results, we used 5\% type-I error with the Bonferroni correction as the genome-wide significance. The $500 \mathrm{k}$ SNP data was estimated to have 276,666 independent SNPs [31]. Each pairwise test was considered to have four independent tests although five effects were tested, because the two-locus marker genotypic effect was confounded with one of the four epistasis effects in reporting significant results. Therefore, the genome-wide 5\% type-I errors with the Bonferroni correction was calculated as $\mathrm{p}=0.05$ $[4(276,666)(276,665) / 2]^{-1}=3.266 \times 10^{-13}$. This $5 \%$ significance level is equivalent to "significant linkage" defined in [16]. Since the Bonferroni correction is generally consid- ered too severe, we also reported epistasis effects reaching "suggestive linkage" with statistical evidence that would be expected to occur one time at random in a genome-wide analysis [16]. In addition to the GLS method to account for sib correlation, the genomic control (GC) method [32] was used to account for potential sub-population structures in the three generation cohort of the FHS data set. For single-locus tests, all p-values were used to estimate inflation parameters for TC and HDL-C, yielding inflation parameter estimates of 1.14 and 1.11 respectively, and test statistics from the GLS tests were then adjusted by the estimates of inflation parameters and p-values were recalculated using the GC adjusted test statistics, which resulted in fewer significant effects. For the pairwise epistasis testing, we randomly selected 50,000 p-values and test statistics from over 466 billion pairwise tests for computational efficiency. Then we estimated the inflation parameters using two samples of 50,000 data points each for TC and HDL-C, yielding inflation parameter estimates of 1.01 and 1.05 respec- 
tively. All p-values were then adjusted using the inflation parameters and such adjustments also resulted in fewer significant epistasis results. Frequency of each subclass in an epistasis effect was calculated and each subclass was required to have a minimal number of five observations. After GC adjustment, QQ plots were made to show deviations of the observed $\mathrm{p}$-values from the expected p-values under the null hypothesis for significant test results for single-locus tests only. QQ plot for epistasis effects were not made because the number of p-values for epistasis tests was too large. Gene locations of significant SNPs were identified according to ENSEMBL [15] and NCBI [14] based on Build 37.0 of the human genome.

\section{List of abbreviations}

GWAS: genome-wide association study. SNP: single nucleotide polymorphism. TC: total cholesterol. HDL-C: high-density lipoprotein cholesterol. LDL-C: low-density lipoprotein cholesterol. LD: linkage disequilibrium. HWD: Hardy-Weinberg disequilibrium. A $\times$ A: additive $\times$ additive epistasis effect. $\mathbf{A} \times \mathbf{D}$ : additive $\times$ dominance epistasis effect. $\mathbf{D} \times \mathbf{A}$ : dominance $\times$ additive epistasis effect. $\mathbf{D} \times \mathbf{D}$ : dominance $\times$ dominance epistasis effect. GLS: generalized least squares.

Competing interests

The authors declare that they have no competing interests.

\section{Authors' contributions}

LM processed the FHS data, implemented the data analysis and prepared the manuscript with YD. JY contributed to the data analysis and manuscript preparation. HBR directed the parallel computing implementation of the GWAS analysis. TT, LF and SB conducted the In Silico replication using the InCHIANTI cohort. YD coordinated this research and prepared the manuscript with LM. All authors read and approved this manuscript.

\section{Acknowledgements \\ This research was supported in part by project MN-16-043 of the Agricultural Experiment Station at the University of Minnesota and by a grant from the Min- nesota Supercomputer Institute. The Framingham Heart Study is conducted and supported by the National Heart, Lung, and Blood Institute (NHLBI) in col- laboration with Boston University. This manuscript was not prepared in collab- oration with investigators of the Framingham Heart Study and does not necessarily reflect the opinions or views of the Framingham Heart Study, Bos- ton University, or the NHLBI. The InCHIANTI study baseline (1998-2000) was supported as a "targeted project" (ICS110.1/RF97.71) by the Italian Ministry of Health and in part by the U.S. National Institute on Aging (Contracts: 263 MD 9164 and 263 MD 821336).}

\section{Author Details \\ 1Department of Animal Science, University of Minnesota, USA ${ }^{2}$ Supercomputer Institute, University of Minnesota, USA, ${ }^{3}$ Medstar Health Research Institute, Baltimore MD, USA, ${ }^{4}$ Longitudinal Study Section, National Institute on Aging, Baltimore MD, USA and ${ }^{5}$ Geriatric Unit, Azienda Sanitaria Firenze (ASF), Florence, Italy}

Received: 23 June 2009 Accepted: 6 April 2010 Published: 6 April 2010

\section{References}

1. Aulchenko YS, Ripatti S, Lindqvist I, Boomsma D, Heid IM, Pramstaller PP, Penninx BWJH, Janssens ACJW, Wilson JF, Spector T, Martin NG, Pedersen NL, Kyvik KO, Kaprio J, Hofman A, Freimer NB, Jarvelin MR, Gyllensten U,
Campbell H, Rudan I, Johansson A, Marroni F, Hayward C, Vitart V, Jonasson I, Pattaro C, Wright A, Hastie N, Pichler I, Hicks AA, Falchi M, Willemsen G, Hottenga JJ, De Geus EJC, Montgomery GW, Whitfield J, Magnusson P, Saharinen J, Perola M, Silander K, Isaacs A, Sijbrands EJG, Uitterlinden AG, Witteman JCM, Oostra BA, Elliott P, Ruokonen A, Sabatti C, Gieger C, Meitinger T, Kronenberg F, Döring A, Wichmann HE, Smit JH, McCarthy MI, Duijn CM, Leena : Loci influencing lipid levels and coronary heart disease risk in 16 European population cohorts. Nat Genet 2008, 41:47-55.

2. Kathiresan S, Willer CJ, Peloso GM, Demissie S, Musunuru K, Schadt EE, Kaplan L, Bennett D, Li Y, Tanaka T, Voight BF, Bonnycastle LL, Jackson AU, Crawford G, Surti A, Guiducci C, Burtt NP, Parish S, Clarke R, Zelenika D, Kubalanza KA, Morken MA, Scott LJ, Stringham HM, Galan P, Swift AJ, Kuusisto J, Bergman RN, Sundvall J, Laakso M, Ferrucci L, Scheet P, Sanna S, Uda M, Yang Q, Lunetta KL, Dupuis J, De Bakker PIW, O'Donnell CJ, Chambers JC, Kooner JS, Hercberg S, Meneton P, Lakatta EG, Scuteri A, Schlessinger D, Tuomilehto J, Collins FS, Groop L, Altshuler D, Collins R, Lathrop GM, Melander O, Salomaa V, Peltonen L, Orho-Melander M, Ordovas JM, Boehnke M, Abecasis GR, Mohlke KL, Cupples LA: Common variants at 30 loci contribute to polygenic dyslipidemia. Nat Genet 2008, 41:56-65.

3. Kathiresan S, Melander O, Guiducci C, Surti A, Burtt NP, Rieder MJ, Cooper GM, Roos C, Voight BF, Havulinna AS, Wahlstrand B, Hedner T, Corella D, Tai ES, Ordovas JM, Berglund G, Vartiainen E, Jousilahti P, Hedblad B, Taskinen M-R, Newton-Cheh C, Salomaa V, Peltonen L, Groop L, Altshuler DM, Orho-Melander M: Six new loci associated with blood low-density lipoprotein cholesterol, high-density lipoprotein cholesterol or triglycerides in humans. Nat Genet 2008, 40:189-197.

4. Willer CJ, Sanna S, Jackson AU, Scuteri A, Bonnycastle LL, Clarke R, Heath SC, Timpson NJ, Najjar SS, Stringham HM, Strait J, Duren WL, Maschio A, Busonero F, Mulas A, Albai G, Swift AJ, Morken MA, Narisu N, Bennett D, Parish S, Shen H, Galan P, Meneton P, Hercberg S, Zelenika D, Chen WM, Li Y, Scott LJ, Scheet PA, Sundvall J, Watanabe RM, Nagaraja R, Ebrahim S, Lawlor DA, Ben-Shlomo Y, Davey-Smith G, Shuldiner AR, Collins R, Bergman RN, Uda M, Tuomilehto J, Cao A, Collins FS, Lakatta E, Lathrop GM, Boehnke M, Schlessinger D, Mohlke KL, Abecasis GR: Newly identified loci that influence lipid concentrations and risk of coronary artery disease. Nat Genet 2008, 40:161-169.

5. Karvanen J, Silander K, Kee F, Tiret L, Salomaa V, Kuulasmaa K, Wiklund PG, Virtamo J, Saarela O, Perret C, Perola M, Peltonen L, Cambien F, Erdmann J, Samani NJ, Schunkert H, Evans A: The impact of newly identified loci on coronary heart disease, stroke and total mortality in the MORGAM prospective cohorts. Genet Epidemiol 2009, 33:237-246.

6. Sandhu MS, Waterworth DM, Debenham SL, Wheeler E, Papadakis K, Zhao JH, Song K, Yuan X, Johnson T, Ashford S, Inouye M, Luben R, Sims M, Hadley D, McArdle W, Barter P, Kesäniemi YA, Mahley RW, McPherson R, Grundy SM, Wellcome Trust Case Control Consortium, Bingham SA, Khaw KT, Loos RJ, Waeber G, Barroso I, Strachan DP, Deloukas P, Vollenweider P, Wareham NJ, Mooser V: LDL-cholesterol concentrations: a genomewide association study. Lancet 2008, 371:483-491.

7. Wallace C, Newhouse SJ, Braund P, Zhang F, Tobin M, Falchi M, Ahmadi K Dobson RJ, Marcano AC, Hajat C, Burton P, Deloukas P, Brown M, Connell JM, Dominiczak A, Lathrop GM, Webster J, Farrall M, Spector T, Samani NJ, Caulfield MJ, Munroe PB: Genome-wide association study identifies genes for biomarkers of cardiovascular disease: Serum urate and dyslipidemia. Am J Hum Genet 2008, 82:139-149.

8. Samani NJ, Braund PS, Erdmann J, Gotz A, Tomaszewski M, Linsel-Nitschke P, Hajat C, Mangino M, Hengstenberg C, Stark K, Ziegler A, Caulfield M, Burton PR, Schunkert H, Tobin MD: The novel genetic variant predisposing to coronary artery disease in the region of the PSRC1 and CELSR2 genes on chromosome 1 associates with serum cholesterol. $J$ Mol Med 2008, 86:1233-1241

9. Nakayama K, Bayasgalan T, Yamanaka K, Kumada M, Gotoh T, Utsumi N, Yanagisawa Y, Okayama M, Kajii E, Ishibashi S, Iwamoto S, The Jichi Community Genetics Team (JCOG): Large scale replication analysis of loci associated with lipid concentrations in a Japanese population. $J$ Med Genet 2009, 46:370-374

10. Schadt EE, Molony C, Chudin E, Hao K, Yang X, Lum PY, Kasarskis A, Zhang B, Wang S, Suver C, Zhu J, Millstein J, Sieberts S, Lamb J, Guha Thakurta D, Derry J, Storey JD, Avila-Campillo I, Kruger MJ, Johnson JM, Rohl CA, van Nas A, Mehrabian M, Drake TA, Lusis AJ, Smith RC, Guengerich FP, Strom 
SC, Schuetz E, Rushmore TH, Ulrich R: Mapping the genetic architecture of gene expression in human liver. PLOS Biol 2008, 6:e107.

11. Kathiresan S, Manning AK, Demissie S, D'Agostino RB, Surti A, Guiducci C, Gianniny L, Burtt NP, Melander O, Orho-Melander M, Arnett DK, Peloso GM, Ordovas JM, Cupples LA: A genome-wide association study for blood lipid phenotypes in the Framingham Heart Study. BMC Med Genet 2007, 19:8(Suppl 1):S17.

12. Murray A, Cluett C, Bandinelli S, Corsi AM, Ferrucci L, Guralnik J, Singleton A, Frayling T, Melzer D: Common lipid-altering gene variants are associated with therapeutic intervention thresholds of lipid levels in older people. Eur Heart J 2009, 30:1711-1719.

13. Mao Y, London NR, Ma L, Dvorkin D, Da Y: Detection of SNP epistasis effects of quantitative traits using an extended Kempthorne model. Physiol Genomics 2007, 28:46-52.

14. National Center for Biotechnology Information: [http:// www.ncbi.nlm.nih.gov]. Last accessed 2/13/2010

15. ENSEMBL Genome Browser: [http://www.ensembl.org/index.html]. Last accessed 2/13/2010

16. Lander ES, Kruglyak L: Genetic dissection of complex traits: guidelines for interpreting and reporting linkage results. Nat Genet 1995, 11:241-247.

17. Friedewald WT, Levy RI, Fredrickson DS: Estimation of the concentration of low-density lipoprotein cholesterol in plasma, without use of the preparative ultracentrifuge. Clin Chem 1972, 18:499-502.

18. Silander K, Alanne M, Kristiansson K, Saarela O, Ripatti S, Auro K, Karvanen J, Kulathinal S, Niemelä M, Ellonen P, Vartiainen E, Jousilahti P, Saarela J, Kuulasmaa K, Evans A, Perola M, Salomaa V, Peltonen L: Gender Differences in Genetic Risk Profiles for Cardiovascular Disease. PLoS ONE 2008, 3:e3615.

19. Tanaka T, Shen J, Abecasis GR, Kisialiou A, Ordovas JM, Guralnik JM, Andrew Singleton A, Bandinelli S, Cherubini A, Arnett D, Tsai MY, Ferrucc L: Genome-Wide Association Study of Plasma Polyunsaturated Fatty Acids in the InCHIANTI Study. PLoS Genet 2009, 5:e1000338.

20. Wostmann BS, Bruckner-Kardoss E: The effect of long-term feeding of $10 \%$ dietary lactose on serum, liver and aortic cholesterol of the rat and the gerbil. J Nutr 1980, 110:82-89.

21. Enattah NS, Sahi T, Savilahti E, Terwilliger JD, Leena Peltonen L, Järvelä l: Identification of a variant associated with adult-type hypolactasia. Nat Genet 2002, 30:233-237.

22. Yan D, Mäyränpää MI, Wong J, Perttilä J, Lehto $M$, Jauhiainen $M$, Kovanen PT, Ehnholm C, Brown AJ, Olkkonen VM: OSBP-related protein 8 (ORP8) suppresses $A B C A 1$ expression and cholesterol efflux from macrophages. J Biol Chem 2007, 283:332-340.

23. Wang J, Burnett JR, Near S, Young K, Zinman B, Hanley AJ, Connelly PW, Harris $S B$, Hegele RA: Common and rare $A B C A 1$ variants affecting plasma HDL cholesterol. Arterioscler Thromb Vasc Biol 2000, 20:1983-1989.

24. Cohen JC, Kiss RS, Pertsemlidis A, Marcel YL, McPherson R, Hobbs HH: Multiple rare alleles contribute to low plasma levels of $\mathrm{HDL}$ cholesterol. Science 2004, 305:869-872.

25. Rutsch F, Gailus S, Miousse IR, Suormala T, Sagné C, Toliat MR, Nurnberg G, Wittkampf T, Buers I, Sharifi A, Stucki M, Becker C, Baumgartner M, Robenek H, Marquardt T, Hohne W, Gasnier B, Rosenblatt DS, Fowler B, Nurnberg P: Identification of a putative lysosomal cobalamin exporter altered in the cbIF defect of vitamin B(12) metabolism. Nat Genet 2009, 41:234-239.

26. Box GEP, Cox DR: An analysis of transformations (with discussion). J Roy Stat Soc B 1964, 26:211-252.

27. R Development Core Team: $\mathrm{R}: \mathrm{A}$ language and environment for statistical computing. [http://www.R-project.org]. R Foundation for Statistical Computing. Vienna, Austria ISBN 3-900051-07-0, 2008. Last accessed 6/22/09

28. Ma L, Runesha HB, Dvorkin D, Garbe JR, Da Y: Parallel and serial computing tools for testing single-locus and epistatic SNP effects of quantitative traits in genome-wide association studies. BMC Bioinformatics 9:315.

29. Ma L, Amos Cl, Yang Da Y: Accounting for correlations among individuals for testing SNP single-locus and epistasis effects in Genome-wide association analysis (Abstract). Plant \& Animal Genomes XVI Conference, January 12-16, San Diego, CA 2008 [http://www.intlpag.org/16/abstracts/PAG16 P11 903.html]. Last accessed 6/22/09
30. Dudbridge F, Gusnanto A: Estimation of significance thresholds for genomewide association scans. Genet Epidemiol 2008, 32:227-234

31. Moskvina V, Schmidt K: On multiple-testing correction in genome-wide association studies. Genet Epidemiol 2008, 32:567-573.

32. Devlin B, Roeder K: Genomic control for association studies. Biometrics 1999, 55:997-1004.

Pre-publication history

The pre-publication history for this paper can be accessed here: http://www.biomedcentral.com/1471-2350/11/55/prepub

doi: 10.1186/1471-2350-11-55

Cite this article as: Ma et al., Genome-wide association analysis of total cholesterol and high-density lipoprotein cholesterol levels using the Framingham Heart Study data BMC Medical Genetics 2010, 11:55

\section{Submit your next manuscript to BioMed Central and take full advantage of:}

- Convenient online submission

- Thorough peer review

- No space constraints or color figure charges

- Immediate publication on acceptance

- Inclusion in PubMed, CAS, Scopus and Google Scholar

- Research which is freely available for redistribution 